\title{
Alergijos jodo turintiems radiokont- rastiniams tirpalams diagnostikos, gydymo ir profilaktikos principai
}

Doc. dr. Jūratè Staikūnienè

KMU Pulmonologijos ir imunologijos klinika

Reikšminiai žodžiai: jodas, radiokontrastiniai tirpalai, alergija, anafilaksija.

Santrauka. Padaugèjus diagnostinių procedūrų, kurių metu reikalingi jodo turintys radiokontrastiniai tirpalai (RKT), dažniau ¿vyksta ir šių preparatų sukeltų nepageidaujamų reakcijų, dalį kurių lemia padidèjęs jautrumas (alergija). Visi RKT gali sukelti greitajją alerginę ir nealerginę anafilaksiją, rečiau lètąją alerginę reakciją, kuri visada pasireiškia odoje. Tikimybė, kad greitojo tipo reakcija pasikartos kito tyrimo su RKT metu yra 21-60 proc. Taigi, jei reikia pakartotinai atlikti diagnostinę ar gydomąją procedūrą su RKT, išsiaiškinus buvusių reakcijų pobūdį, reikia pasirinkti kitą nejoninį mažo osmosiškumo tirpalą ir taikyti premedikaciją. Vis dèlto premedikacija gliukokortikoidais ir antihistamininiais vaistais neapsaugo nuo anafilaksijos, tik sumažina reakcijos sunkumą, dèl to gydytojui svarbu atpažinti alerginės reakcijos požymius ir nedelsiant juos gydyti.

Su intraveniniais jodo turinčiais radiokontrastiniais tirpalais (RKT) kasmet pasaulyje atliekama daugiau negu 70 milijonų tyrimų. Radiokontrastinių tirpalų sukeltų greitųjų nepageidaujamų reakcijų dažnumas priklauso nuo tirpalo savybių, ypač osmosiškumo. Intraveniniai joniniai didelio osmosiškumo RKT lengvos eigos nepageidaujamų reakcijų sukelia 3,8-12,7 proc. atvejų, sunkios eigos $-0,1-0,4$ proc. atvejų. I veną skiriami nejoniniai mažo osmosiškumo RKT lengvos eigos nepageidaujamų reakcijų sukelia $0,7-3,1$ proc. atvejų, sunkios eigos - 0,02-0,04 proc. atvejų. Taigi, nors nepageidaujamų reakcijų dažnumas ir sunkumas ženkliai sumažèjo, vis dèlto ir vartojant nejoninius mažo osmosiškumo RKT miršta 1 iš 100 tūkst. tiriamujuc, o mirštamumas naudojant joninius ir nejoninius RKT nesiskiria.

\section{JODO TURINČIŲ RADIOKONTRASTINIŲ TIRPALŲ KLASIFIKACIJA IR SAVYBĖS}

Pirmąji netoksišką jodo turintị radiokontrastinị tirpalą sukūrè ir sèkmingai panaudojo diagnostiniams tyrimams internas Moses Swick 1929 m. Sujungęs du piridono žiedus su dviem jodo atomais, jis paruošè diagnostinị tirpalą, kurị sėkmingai naudojo dvidešimt metų. Be to, jis padejo sukurti ir benzeno žiede tris jodo atomus turinčius tirpalus, kurių pagrindiniai at-

1 lentelè. DAŽNIAUSIAI VARTOJAMŲ RADIOKONTRASTINIŲ TIRPALŲ KLASIFIKACIJA

\begin{tabular}{|c|c|c|}
\hline Grupè & Veiklioji medžiaga & Pavadinimas \\
\hline $\begin{array}{l}\text { Joninis hiperosmosinis } \\
\text { (monomerinis RKT) }\end{array}$ & $\begin{array}{l}\text { Ac.amidotrizoicum } \\
\text { (natrio, meglumino } \\
\text { druska) } \\
\text { Ioxytalamate }\end{array}$ & $\begin{array}{l}\text { Urografin } \\
\text { Radiolselectan } \\
\text { Telebrix }\end{array}$ \\
\hline $\begin{array}{l}\text { Joninis mažo osmosiš- } \\
\text { kumo (dimerinis RKT) }\end{array}$ & Ioxaglate & Hexabrix \\
\hline $\begin{array}{l}\text { Nejoninis mažo } \\
\text { osmosiškumo } \\
\text { (monomerinis RKT) }\end{array}$ & $\begin{array}{l}\text { Iobitridol } \\
\text { Iohexol } \\
\text { Iomeprol } \\
\text { Iopamidol } \\
\text { Iopentol } \\
\text { Iopromide } \\
\text { Ioversol }\end{array}$ & $\begin{array}{l}\text { Xenetix } \\
\text { Omnipaque } \\
\text { Iomeron } \\
\text { Iopamiro } \\
\text { Ivepaque } \\
\text { Ultravist } \\
\text { Optiject }\end{array}$ \\
\hline $\begin{array}{l}\text { Nejoninis izoosmosinis } \\
\text { (dimerinis RKT) }\end{array}$ & Iodixanol & Visipaque \\
\hline
\end{tabular}




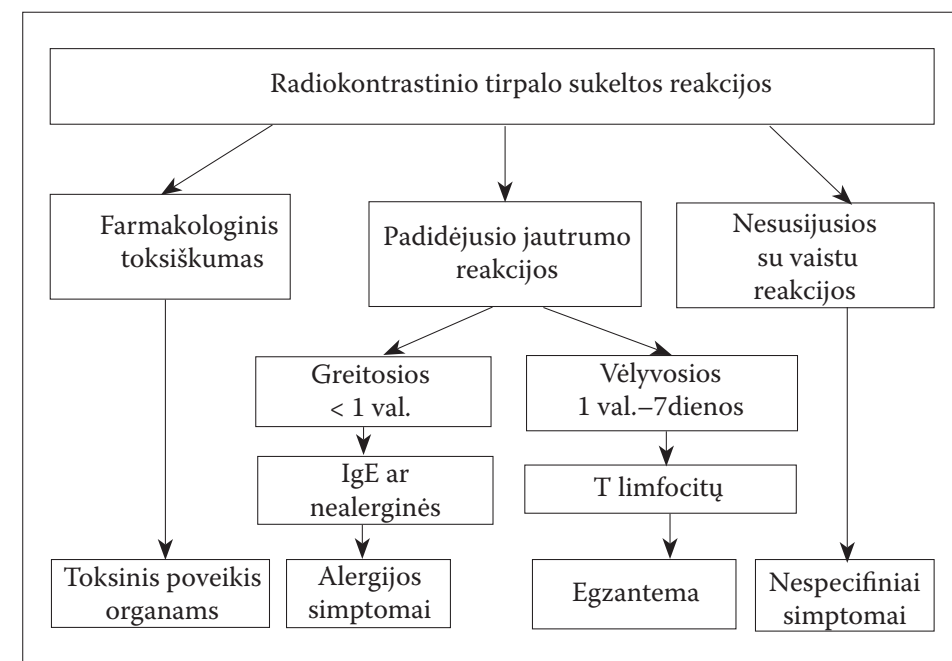

1 pav. RADIOKONTRASTINIŲ TIRPALU SUKELTŲ NEPAGEIDAUJAMŲ REAKCIJŲ KLASIFIKACIJA

stovai buvo diatrizoatas ar joksitalamatas (1 lentelè). Kadangi šie joduoti joniniai monomeriniai kontrastiniai tirpalai penkis kartus viršija kraujo plazmos osmosiškumą, suleisti jie sukelia pykinimą, vẻmimą, gali skaudèti injekcijos vietą, atsirasti tromboflebitas, pasižymi neigiamu inotropiniu ir chronotropiniu poveikiu. Prieš du dešimtmečius buvo sukurtas pirmasis nejoninis (neturintis joninès karboksi COO-grupès) monomerinis triju jodo atomų kontrastinis tirpalas metrizamidas. Šio tirpalo osmosiškumas gerokai mažesnis, dèl to jis nesukelia minètų nepageidaujamų reiškinių. Ilgainiui buvo sukurtas joninis dimeras joksaglatas, turintis du benzeno žiedus su jonine bei nejonine jungtimi ir šešiais jodo atomais, kurio savybès nesiskiria nuo nejoninių monomerų. Naujausi radiokontrastiniai tirpalai yra nejoniniai dimerai, pavyzdžiui, jodiksanolis, kurio osmosiškumas toks pat kaip plazmos (izoosmosiškas), ir nepageidaujamą poveiki sukelia itin retai.

\section{JODO TURINČIŲ RADIOKONTRASTINIŲ TIRPALŲ SUKELTOS NEPAGEIDAUJAMOS REAKCIJOS IR JŲ DIAGNOSTIKA}

Visi jodo turintys joniniai ir nejoniniai radiokontrastiniai tirpalai gali sukelti nepageidaujamų reakcijų, kurios pasireiškia odos išbėrimais, kvėpavimo ar kraujotakos sutrikimais. Joniniai didelio osmosiškumo monomerai daug dažniau sukelia nepageidaujamų reakcijų negu nejoniniai. RKT sukeltos nepageidaujamos reakcijos yra skiriamos ị toksines, nespecifines, nesusijusias su tirpalu ir padidejusio jautrumo (1 pav.). Greitosios padidejusio jautrumo reakcijos išsivysto per pirmąją valandą po RKT suleidimo, 70 proc. iš jų per pirmąsias penkias minutes. Jos gali būti E klasės imunoglobulino (IgE) sukeltos ar nealerginès (pseudoalerginès). Yra duomenų, kad greitosios reakcijos vyksta dèl tiesioginès histamino liberacijos iš bazofiluc, putliụjų ląstelių ir komplemento sistemos suaktyvejjimo. Vèlyvosios padidejusio jautrumo reakcijos yra sąlygotos $\mathrm{T}$ limfocitų ir prasideda praejjus 1 valandai ar septynių dienų laikotarpiu po RKT panaudojimo.

Greitųjų alerginių ir nealerginių reakcijų klinikiniai požymiai nesiskiria ir svyruoja nuo lengvų, pasireiškiančių odos niežèjimu, paraudimu, dilgèlinès pobūdžio išbèrimu (70 proc. atvejų ) iki sisteminių ir gyvybei pavojingos anafilaksijos. Taip pat gali prasidèti angioedema, išryškėti virškinimo sistemos (pykinimas, viduriavimas, pilvo skausmai), kvėpavimo sistemos (čiaudulys, rinorèja, kosulys, balso prikimimas, dusulys dèl gerklu edemos, bronchospazmo) ar širdies ir kraujagysliuc sistemos simptomų (hipotenzija, tachikardija, aritmija). Anafilaksija yra gyvybei grèsminga, žaibiškai besivystanti alerginè reakcija, kuri paprastai pažeidžia dvi iš keturių organų sistemų: odos, kvejpavimo, kraujotakos ir virškinimo. Sunkiausias variantas yra anafilaksinis šokas, mirštama nuo širdies ar kvèpavimo sustojimo.

Lètosios RKT sukeltos alerginès reakcijos pasireiškia 1-3 proc. atvejų, net pusè jų - makuliniu ar makulopapuliniu odos išbèrimu (egzantema). Kitos dažnos vèlyvosios reakcijos - odos niežéjimas, paraudimas, dilgèlinè, angioedema - būna nesunkios eigos, neišplitusios. Literatūros šaltinuose aprašyta ir gyvybei grèsmingų sisteminių vėlyvųjų reakcijų, kaip antai: Stevens-Johnson sindromas, toksinè epidermio nekrolizė (Lyell sindromas), odos vaskulitas. Aprašyti ir keli atvejai vẻlyvosios angioedemos ir hipotenzijos ar dusulio derinių, dvifazè reakcija.

Diagnozuojant RKT, kaip ir kitu vaistų, sukeltas nepageidaujamas reakcijas labai svarbu anamnezè ir klinikiniai požymiai, nes nẻra vieno alergiją patvirtinančio tyrimo. Reikia išsiaiškinti, kokie buvo objektyvūs simptomai, odos išbėrimų pobūdis, vieta, trukmé, jų daugejjimas kito tyrimo metu. Požymių atsiradimo laikas po vaisto dozès padeda suklasifikuoti reakciją i ankstyvąją ir vèlyvąją. Jei reakcija praejjo savaime negydoma, vadinasi, buvo nesunkios eigos, jei simptomai išnyko paskyrus gydymą - vidutinio sunkumo. Jei pacientas buvo hospitalizuotas, pasireiškè gyvybei grèsmingų požymių, nepageidaujama reakcija yra sunkios eigos. Neretai pacientas pats negali apibūdinti reakcijos, dèl to reikšmingi ji gydžiusio gydytojo įrašai apie vartotą RKT ir jo sukeltą nepageidaujamą reakciją. Anamnezès duomenys apie kitų vaistų ar biologinių preparatuc sukeltas reakcijas, atopiją, astmą, kitas alergines ligas padeda išsiaiškinti RKT sukeltų nepageidaujamų reakcijų rizikos veiksnius.

Ivykus greitojo tipo nepageidaujamai reakcijai i RKT, 1-2 val. laikotarpiu kraujo serume nustatomas padidèjęs triptazès kiekis, kuris būna sumažejęęs tiriant pakartotinai po 1-2 d. Histamino kiekis padideja greičiau, didžiausia jo koncentracija susidaro po 5-10 min. ir grịžta i pradini lygi 1 val. laikotarpiu. Deja, šių mediatorių kiekis padideja tik sunkios ar net mirtinos anafilaksijos atvejais, diagnostinè šiu tyrimų vertè nèra nustatyta. Odos mėginiai su RKT atliekami 6 mènesių laikotarpiu, ne anksčiau negu 4-6 savaitès po ịvykusios reakcijos. Odos dūrio mèginiai atliekami su neskiestu RKT, įodinis 
mėginys su nuo 1000 iki 10 kartų praskiestu tirpalu. Šių tyrimų jautrumas diagnozuojant IgE sąlygotą alerginę reakciją i RKT nèra nustatytas, juos atliekant net 11 proc. tiriamųjų pasireiškia alerginių sisteminių reakcijų. RKT specifinių IgE serume nustatoma nuo 2 iki 47 proc. pacientų, kuriems įvyko sunkios eigos anafilaksija. Ne tik specifiniu IgE, bet ir bazofilu aktyvinimo, histamino atpalaidavimo tyrimu in vitro vertè diagnozuojant alergiją RKT nenustatyta.

Jei įvyko lètojo tipo nepageidaujama reakcija naudojant RKT, ūminiu periodu rekomenduojama ištirti, ar nèra pažeistų vidaus organų. Reikia ištirti kraujyje eozinofilų kiekị, kepenų fermentų aktyvumą, azotemijos rodmenis. Odos biopsinès medžiagos iš išbèrimo vietos histologinis tyrimas padeda atskirti reakciją nuo kitų odos pažeidimų, rezultatai turi būti derinami su kitais klinikiniais požymiais. Gali būti eozinofilų degeneracija, neutrofilų abscesų, limfocitų, histiocitų, eozinofilu infiltratų dermoje ar apie kraujagysles, epidermio spongiozè, nekrozè, pūslès ir kt. Pokyčiai nespecifiniai, tačiau padeda nustatyti reakcijos mechanizmą. Pasveikus atliekami odos mėginiai: lopo, dūrio ir įodiniai, kurie vertinami po 1, 3 ar 4 dienų, net ir po savaitès, jei rezultatas neigiamas. Limfocitu aktyvinimo in vitro méginiai klinikineje praktikoje neatliekami. Provokacinis mėginys su RKT dèl anafilaksijos rizikos nerekomenduojamas.

\section{RADIOKONTRASTINIŲ TIRPALŲ SUKELTUৃ NEPAGEIDAUJAMŲ REAKCIJŲ GYDYMAS}

Alerginių ir nealerginių greitųjų reakcijų gydymas nesiskiria, gydoma pagal anafilaksijos gydymo algoritmą (2 pav.). Svarbiausia yra kuo anksčiau atpažinti anafilaksijos požymius ir nedelsiant pradèti gydymą adrenalinu. Adrenalino dozè yra 0,3-0,5 $\mathrm{ml} \mathrm{0,1}$ proc. tirpalo $(0,3-0,5 \mathrm{mg})$ i raumenis kartojama kas 5-20 minučių. I veną galima leisti tik praskiesto 0,01 proc. 1-2 ml (0,1-0,2 mg) adrenalino tirpalo. Simptomams slopinti skiriama sisteminio poveikio gliukokortikoidų, antihistamininiu vaistų, jei yra bronchų spazmas, inhaliuojamojo salbutamolio, deguonies terapija. Gydant anafilaksiją svarbu leisti daug skysčių i veną. Vartojantiems beta adrenoblokatorius pacientams anafilaksijai gydyti reikia leisti gliukagono po 1-2 mg kas 5 min. ì v. ar ì r. Pacientą, kuriam įvyko anafilaksija, būtina stebèti 24 valandas. Gydytojas turi aprašyti RKT sukeltą nepageidaujamą reakciją medicinos dokumentuose, kad ateityje jos būtų galima išvengti.

\section{KADA TAIKYTI RKT NEPAGEIDAUJAMŲ REAKCIJŲ PROFILAKTIKĄ}

Tikimybè, kad greitojo tipo reakcija pasikartos kito tyrimo su RKT metu yra 21-60 proc., todèl planuojant atlikti tyrimą su radiokontrastiniu preparatu būtina ivertinti naudos ir rizikos santykị, pasirinkti kitus diagnostinius tyrimus, kuriems nereikalingas RKT (magnetinio rezonanso, ultragarso tyrimą). Greitųjų anafilak-

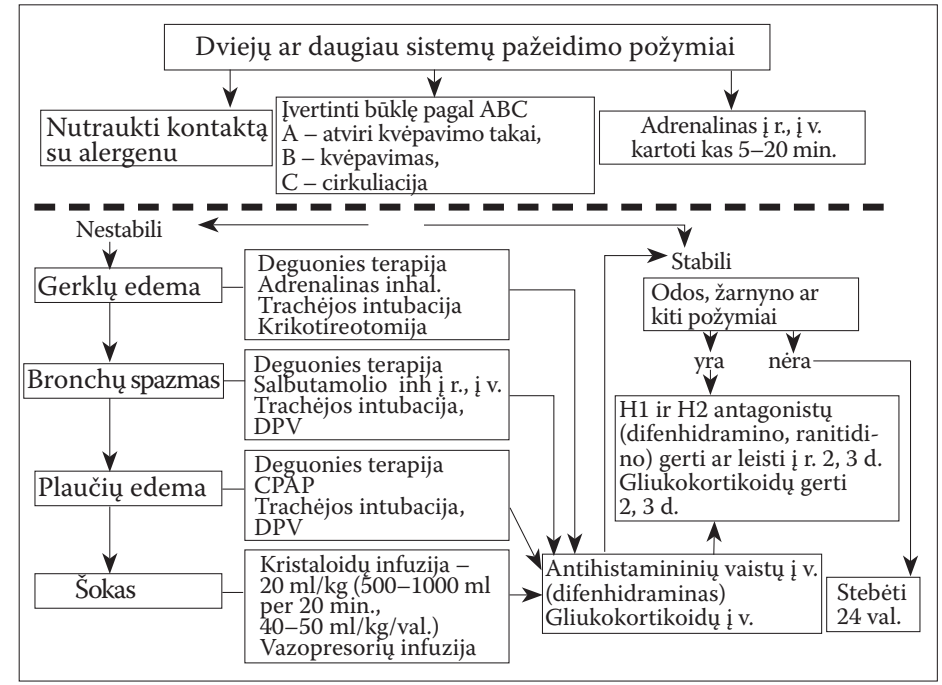

2 pav. PAGALBOS ANAFILAKSIJOS ATVEJAIS ALGORITMAS

sinių ir lètojo tipo nepageidaujamų reakcijų rizikos veiksniai skiriasi (2 lentelè). Anafilaksijos tikimybè sumažéja dešimt kartų vartojant nejoninius RKT, kurie pasirenkami vis dažniau, tačiau, jei anksčiau buvo naudotas joninis RKT, gali būti kryžminių alerginių reakcijų ì kitą nejonini preparatą. Kai Greenberger irode, kad premedikacija gliukokortikoidais, antihistamininiais vaistais su efedrinu ar be jo gali apsaugoti nuo didelio osmosiškumo joninių RKT sukeliamų sunkių anafilaksinių reakcijų, klinikinejje praktikoje vis dažniau skiriami įvairūs šių vaistų deriniai, taikomos ivairios jų vartojimo schemos. Tačiau atliktuose klinikiniuose tyrimuose premedikacijai buvo vartojami arba tik gliukokortikoidai, arba tik antihistamininiai vaistai, ir nėra atliktų klinikinių tyrimų, kuriais būtų įvertintas šių vaistų derinys su efedrinu ar be jo, vartojami efektyvesni antrosios kartos $\mathrm{H} 1$ antihistamininiai vaistai, ar tiriami tik tie pacientai, kuriems jau pasireiške anafilaksiniu reakcijų. M. R. Tramer su bendradarbiais, atlikę klinikinių tyrimų rezultatų metaanalizę, padarè išvadas, kad pakartotinès gliukokortikoidų dozès 12 ir 2 valandos iki procedūros sumažino kvėpavimo sistemos simptomų dažnumą nuo 1,4 proc. iki 0,4 proc.,

2 lentelè. RADIOKONTRASTINIŲ TIRPALŲ SUKELTŲ NEPAGEIDAUJAMŲ REAKCIJŲ RIZIKOS VEIKSNIAI

\begin{tabular}{|c|c|}
\hline $\begin{array}{l}\text { Greitosios (<1 val.) alerginės } \\
\text { reakcijos rizikos veiksniai }\end{array}$ & $\begin{array}{l}\text { Lètosios ( } 1 \text { val. }-7 \mathrm{~d} \text {.) alerginès } \\
\text { reakcijos rizikos veiksniai }\end{array}$ \\
\hline $\begin{array}{l}\text { - Buvusi anafilaksija } \\
\text { - Atopija } \\
\text { - Astma } \\
\text { - Mastocitozė } \\
\text { - Didelè RKT dozė } \\
\text { - Širdies, metabolinės ligos } \\
\text { ( } \beta \text { blokatorių vartojimas) } \\
\text { - Injekcijos būdas ir greitis } \\
\text { - Moteriškoji lytis } \\
\text { - Amžius (20-50m.) } \\
\text { - Nerimas } \\
\text { - Virusinè infekcija, sisteminè } \\
\text { raudonoji vilkligè }\end{array}$ & $\begin{array}{l}\text { - Alergija RKT anamnezėje } \\
\text { - Gydymas interleukinu IL } 2 \\
\text { - Padidèjęs kreatinino kiekis } \\
\text { serume } \\
\text { - Alergija vaistams ar kontaktinis } \\
\text { dermatitas anamnezėje. }\end{array}$ \\
\hline
\end{tabular}


3 lentelè. ADAPTUOTA PREMEDIKACIJOS PRIEŠ RADIOKONTRASTINI TYRIMĄ SCHEMA

\begin{tabular}{lll}
\hline Vaistas & Dozė & $\begin{array}{l}\text { Laikas iki } \\
\text { procedüros }\end{array}$ \\
\hline Prednizolonas & $\begin{array}{l}50-60 \mathrm{mg} \text { gerti, ì } \\
\text { veną }\end{array}$ & $1,7,13 \mathrm{val}$. \\
& & \\
\hline $\begin{array}{l}\text { H1 antihistamininiai } \\
\text { vaistai } \\
\text { (clemastinum) }\end{array}$ & $\begin{array}{l}0,03 \mathrm{mg} / \mathrm{kg}(2 \mathrm{mg}) \text { i } \\
\text { raumenis }\end{array}$ & $1,13 \mathrm{val}$. \\
\hline $\begin{array}{l}\text { H2 antihistamininiai } \\
\text { vaistai } \\
\text { (cimetidinum, }\end{array}$ & $\begin{array}{l}2-5 \mathrm{mg} / \mathrm{kg} \text { ị veną, } \\
\text { ranitidinum })^{*}\end{array}$ & $1,13 \mathrm{val}$. \\
\hline
\end{tabular}

* Neprivalomi, duomenys apie jų efektyvumą skiriasi

o gyvybei grèsmingų kvèpavimo bei širdies ir kraujagysliu sistemų - nuo 0,9 proc. iki 0,2 proc. Odos simptomus reikšmingai sumažino gliukokortikoidai, H1 antihistamininiai vaistai (klemastinas, hidroksizinas, chlorfeniraminas) ar ju derinys su cimetidinu.

Klaidingai manoma, kad premedikacija gliukokortikoidais ir antihistamininiais vaistais apsaugo tiriamąji nuo anafilaksinès reakcijos i RKT. Nors reakcijos sunkumas sumažeja, anafilaksijos rizika esti 0,5-10 proc. Premedikacija turi ir trūkumų, taigi negali būti taikoma visiems tiriamiesiems. Premedikacijai skiriamos kartotinès vaistų dozès, sugaištamas laikas, atidedama invazinė gyvybę gelbstinti procedūra, vaistai, ypač gliukokortikoidai, gali sukelti šalutini poveikị. Premedikacija suteikia tariamą saugumo jausmą tyrèjui ir procedūrą atliekančiam personalui, dèl to gali būti nepastebèti pirmieji anafilaksijos požymiai. Premedikacija gliukokortikoidais ir antihistamininiais vaistais rekomenduo- jama tik tiems pacientams, kurie turi rizikos veiksnių, kurie jau yra patyrę greitojo tipo nepageidaujamą sisteminę reakciją i RKT, kitos etiologijos anafilaksija, serga keletu alerginiu liguc, astma (3 lentelè). Jei reikia skubiai atlikti radiokontrastinị tyrimą, skiriama tik viena vaistų dozė prieš procedūrą. Tačiau premedikacija neefektyvi, jei išsivystė IgE sukeliama alergija ar buvo lètojo tipo RKT sukelta nepageidaujama reakcija, šiais atvejais apsispręsti padeda gydytojai alergologai ir klinikiniai imunologai.

\section{PREVENTION, MANAGEMENT AND DIAGNOSIS OF HYPERSENSITIVITY REACTIONS DUE TO IODINATED RADIOCONTRAST MEDIA}

\section{JÜRATE் STAIKŪNIENÉ \\ DEPARTMENT OF PULMONOLOGY AND IMMUNOLOGY KAUNAS UNIVERSITY OF MEDICINE}

Key words: iodum, radiocontrast media, hypersensitivity, anaphylaxis. Summary. lodinated radiocontrast media (RCM) is used commonly in clinical practice and can be associated with significant adverse effects including hypersensitivity. All RCM are known to cause immediate anaphylactic reactions and nonimmediate hypersensitivity reactions, most of them delayed skin reactions. Previous reactors have a 21-60\% risk of a repeat reaction when re-exposed to the same or a similar RCM. In a case if re-exposure is required after the type of a previous reaction has been determined, another RCM product should be chosen and a premedication applied. However because the premedication with glucocorticosteroids and antihistamines is not a guarantee against a repeat anaphylactic reaction and can only reduce the severity of reaction, the symptoms of allergic reactions must be recognized by physicians and the treatment started promptly.

\section{LITERATŪRA}

1. Broskow $\mathrm{K}$ et al. Management of hypersensitivity reactions to iodinated contrast media. Allergy 2005;60:150-158.

2. Katayama $\mathrm{H}$, Yamaguchi $\mathrm{K}$, KozukanT et al. Adverse reactions to ionic and nonionic contrast media: a report from the Japanese Committee on the Safety of Contrast Media. Radiology 1990;175:621-628.

3. Lieberman PL, Seigle RL. Reactions to radiocontrast material. Clinical Reviews in Allergy and Immunology 1999;17:469-496.

4. Webb JA, Stacul F, Thomsen HS et al. Late adverse reactions to intravascular iodinated contrast media. Eur Radiol 2003;13:181-4.

5. Anderson JA. Allergic and allergic-like reactions to drugs and other therapeutic agents. From: Current clinical practice: Allergic diseases, diagnosis and treatment. 3rd ed. Edited by P.Lieberman and J.A. Anderson., Humana Press, NJ 2007 p.295-318.

6. Christiansen C, Pichler WJ, Skotland T. Delayed allergy-like reactions to X-ray contrast media: mechanistic considerations. Eur Radiol 2000;10:1965-75.

7. Carro JJ Trindade E, McGregor M. The risks of death and of severe nonfatal reactions with high -vs low-osmolality contrast media: a meta analysis. Am J Roentgenol 1991;156:825-832.

8. Demoly P, Kropf R, Bircher A, Pichler WJ. Drug hypersensitivity: questionnaire Allergy;1999;54:999-1003.

9. Ponvert C. Valeurs diagnostique et prédictive des tests cutanés aux médicaments et substances biologiques. Revue Francaise d'Allergologie

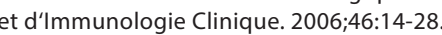

10. Pumphrey RSH. Lessons for the management of anaphylaxis from study of fatal reactions. Clin Exp Allergy 2000;30:1144-50.

11. Blažienè A, Dubakienè R, Ėmužytè R, ir kt. Anafilaksija (sutarimas), Vilnius 2002

12. Morcos SK, Thomsen HS, Webb JA. Prevention of generalized reactions to radiocontrast media: a consensus report and guidelines. Eur Radiol 2001;11:1720-8

13. Greenberger PA, Patterson R. The prevention of immediate generalized reactions to radiocontrast media in high-risk patients. JAC 1991:87:867-72.

14. Liccardi G, Lobefalo G, Di Florio E et al. Strategies for the prevention of asthmatic, anaphylactic and anaphylactoid reactions during the administration of anesthetics and/or contrast media. J Investig Allergol Clin Immunol 2008;18:1-11.

15. Tramer MR, von Elm E, Loubeyre $P$, Hauser $C$. Pharmacological prevention of serious anaphylactic reactions due to iodinated contrast media: systematic review. BMJ 2006;333:675-8.

16. Worthley DL, Gillis D, Kette F, Smith W. Radiocontrast anaphylaxis with failure of premedication. Internal Medicine Journal 2005;35:58-60. 